trachea, creating a pig bronchus (bronchus suis), was accomplished. Full mobilization of the hilar vessels and an aggressive hilar release allowed this to be done without transection of any vessels. Carinal reconstruction was followed by anastomosing the secondary carina, which had a similar circumference to the RMB, directly to the carina. This technique allowed complete preservation of lung parenchyma. In the years before this diagnosis, the patient was thought to have a sedentary personality because he tired easily and did not participate in athletic activities. A year after resection, this eighth grader with a widely patent and nonobstructed airway is running varsity cross-country. We hope that his com- plete parenchyma-sparing airway resection contributed to his excellent functional outcome.

\section{References}

1. Andrassy RJ, Feldtman RW, Stanford W. Bronchial carcinoid tumors in children and adolescents. J Pediatr Surg. 1977;12:513-7.

2. Ferguson MK, Landreneau RJ, Hazelrigg SR, Altorki NK, Naunheim KS, Zwischenberger JB, et al. Long-term outcome after resection for bronchial carcinoid tumors. Eur J Cardiothorac Surg. 2000;18:156-61.

3. Filosso PL, Rena O, Donati G, Casadio C, Ruffini E, Papalia E, et al. Bronchial carcinoid tumors: surgical management and long-term outcome. J Thorac Cardiovasc Surg. 2002; 123:303-9.

4. McMullan DM, Wood DE. Pulmonary carcinoid tumors. Semin Thorac Cardiovasc Surg. 2003;15:289-300.

\title{
Use of unidirectional endobronchial valves for the treatment of giant emphysematous bulla
}

\author{
Mario Santini, MD, Alfonso Fiorello, MD, Vincenzo Giuseppe Di Crescenzo, MD, \\ Giovanni Vicidomini, MD, PhD, Luigi Busiello, MD, and Paolo Laperuta, MD, Naples, Italy
}

We report the successful treatment of a giant emphysematous bulla (GEB) by bronchoscopic placement of unidirectional endobronchial valve (EBV; Zephyr; Emphasys Medical, Inc, Redwood City, Calif) in a patient not able to undergo open thoracotomy.

\section{CLINICAL SUMMARY}

A 68-year-old man who had a history of emphysema and recurrent left pneumothorax treated by pleurodesis with video-assisted thoracoscopic surgery 7 months previously was admitted at our hospital because of dyspnea. All laboratory examinations returned normal results. Blood gas values with room air were as follows: $\mathrm{pH} 7.4, \mathrm{PCO}_{2} 36.2 \mathrm{~mm} \mathrm{Hg}$, and $\mathrm{Po}_{2} 64.9 \mathrm{~mm} \mathrm{Hg}$. The forced vital capacity was 1.35 $\mathrm{L}$ ( $49 \%$ of predicted) with a forced expiratory volume in 1 second of $1.2 \mathrm{~L}$ ( $51 \%$ of predicted).

Computed tomography showed multiple bullae, with a single, larger bulla occupying almost the entire left upper hemithorax and causing pulmonary compression and a mediastinal shift to right (Figure 1, $A$ ).

From the Thoracic Surgery Unit, Second University of Naples, Naples, Italy. Received for publication April 14, 2008; accepted for publication May 5, 2008; available ahead of print Feb 5, 2009.

Address for reprints: Mario Santini, MD, Chirurgia Toracica-Seconda Università di Napoli, Piazza Miraglia, 2, I-80138 Naples, Italy (E-mail: mario.santini@unina2.it). J Thorac Cardiovasc Surg 2010;139:224-6

$0022-5223 / \$ 36.00$

Copyright (C) 2010 by The American Association for Thoracic Surgery doi:10.1016/j.jtcvs.2008.05.069
Previous pleurodesis and poor respiratory condition of the patient discouraged us from performing bullectomy, and the patient was reviewed for endobronchial treatment. We hypothesized that EBVs deflating the bulla might promote the re-lexpansion of the compressed adjacent lungs and improve respiratory function. After informed consent had been obtained, the patient was brought to operating room. A general anesthetic was used to ensure good control of ventilation and cough during the procedure. Anesthesia was induced, and the patient was intubated with an endotracheal tube (size 9.0) to reduce the need for high airway pressures during bronchoscopy and manual ventilation. Flexible bronchoscopy was performed, and examination of the segmental airway anatomy showed compression of the left lower bronchus. According to the instructions supplied with the valve, ${ }^{1}$ two Zephyr 4.0 EBVs were sequentially positioned into the superior trunk bronchus (culmen) of the left upper lobe and into the lingular bronchus (Figure 2, A). Subjective improvement of dyspnea, with diminution in size of the bulla and centralization of mediastinum visible on chest radiography, were noted just the next day. The patient was discharged on postoperative day 5 .

As of 1 month after the procedure, the patient was doing well without recurrence of the pneumothorax. Respiratory function test results showed a forced vital capacity of $1.85 \mathrm{~L}$ ( $67 \%$ of predicted) and a forced expiratory volume in 1 second of $1.7 \mathrm{~L}$ ( $70 \%$ of predicted). The valves have remained in place, and no attempts at removal have been made. Computed tomography showed an almost complete disappearance of the bulla, with re-expansion of the neighboring lung (Figure 1,B). 


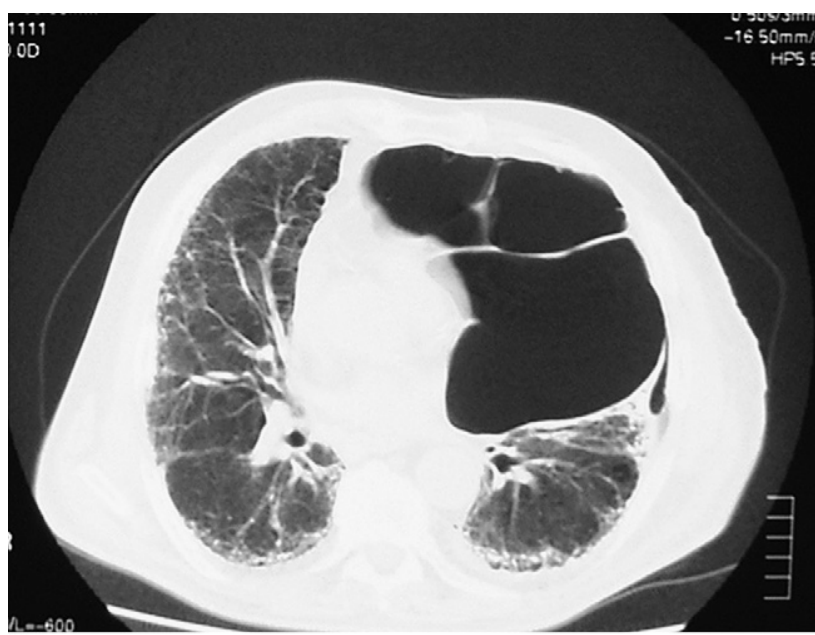

A

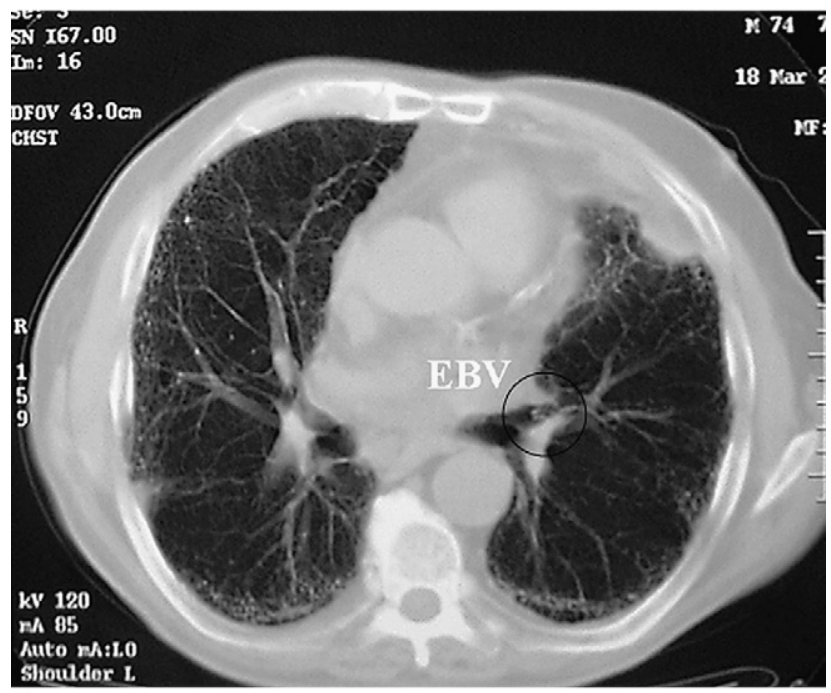

B

FIGURE 1. Computed tomography shows large bulla (15 cm diameter) occupying almost entire left upper hemithorax, with pulmonary compression and mediastinal shift to the right (A). After placement of endobronchial valves, there is complete disappearance of bulla, with re-expansion of neighboring lung and centralization of mediastinum. Exact position of EBV is assessed with radiologic evaluation (B).

\section{DISCUSSION}

A giant bulla is defined as a large bulla occupying at least a third of a hemithorax. Emphysema is commonly association with bullae. A GEB compresses the adjacent lung tissue and impairs respiratory function. Bullectomy, the treatment of choice, produces significant improvements in pulmonary function. ${ }^{2}$ Severe respiratory failure from GEB in a patient who may not be able to tolerate surgical resection, however, is a challenging problem.

Our patient had borderline respiratory function because of a GEB that occupied the left upper hemithorax and caused collapse of the adjacent lung parenchyma with mediastinal shift. Several strategies were investigated for treating the
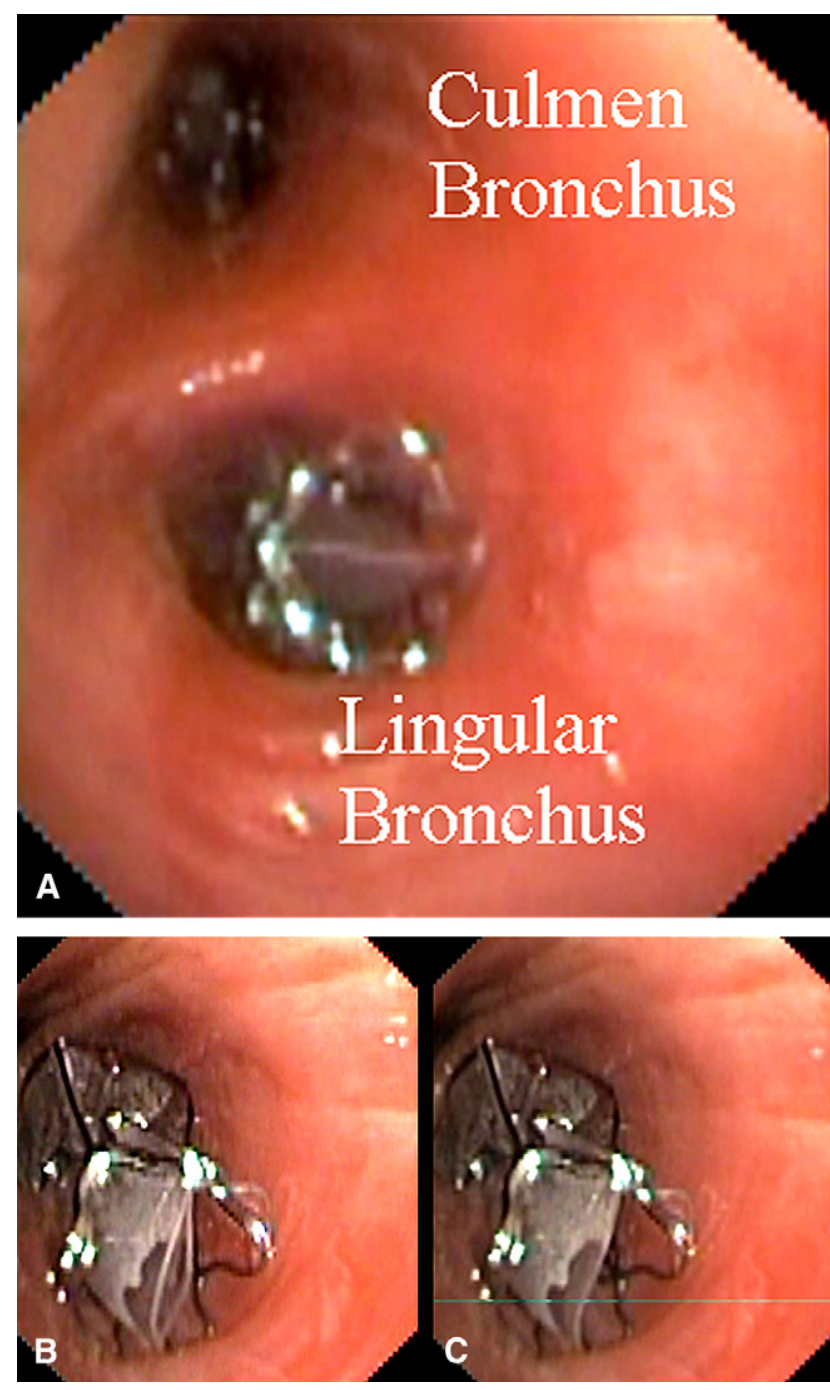

FIGURE 2. Photograph illustrates Zephyr 4.0 endobronchial valves positioned in superior trunk bronchus (culmen) and in lingular bronchus with resulting complete occlusion of left upper lobe (A). Endobronchial valve works like Heimlich valve, allowing escape of air from bulla at expiration (B) but preventing air inflow at inspiration (C).

GEB in a way that would avoid tension pneumothorax and improve respiratory function.

We decided against surgical treatment of the bulla. The possible postoperative adhesions suggest that video-assisted thoracoscopic surgery was unlikely to be successful, and the overall condition of the patient did not favor an open thoracotomy.

An attempt to decompress the bulla with a needle or a chest tube would most likely have resulted in a tension pneumothorax. Macarthur and Fountain ${ }^{3}$ have proposed the intracavity suction and drainage of emphysematous bulla as a less invasive treatment. We rejected this procedure, however, because the drainage often ends in failure for the prolonged air leakage. 
Recently, Bhattacharyya and colleagues ${ }^{4}$ reported a case of decompression of an emphysematous bulla through a transbronchial aspiration needle. We considered this strategy to be unsuitable for our case because of the high risk of pneumothorax or bronchopleural fistula.

Finally, we considered using EBVs, which were designed for the treatment of emphysema and have been applied successfully for occlusion of bronchopleural ${ }^{1}$ and bronchocutaneous $^{5}$ fistulas. The EBVs work like a Heimlich valve, allowing escape of air and secretions from bulla at expiration (Figure 2,B) but preventing air inflow at inspiration (Figure $2, C$ ), thus resulting in a redirection of airflow away from the blocked segments. The result is deflation of the GEB and the re-expansion of the more normal adjacent lung.

Our experience confirms that this noninvasive bronchoscopic treatment may represent a valuable alternative for patients who are poor surgical candidates. Bronchoscopic
EBV insertion is easily placed by a thoracic surgeon familiar with interventional endoscopic procedures, well tolerated, and easily removed if necessary. Large series and longterm trials are needed for adequate validation of the technique described.

\section{References}

1. Anile M, Venuta F, De Giacomo T, Rendina EA, Diso D, Pugliese F, et al. Treatment of persistent air leakage with endobronchial one-way valves. J Thorac Cardiovasc Surg. 2006;132:711-2.

2. Gordon LS. Reduction pneumoplasty for giant bullous emphysema. Chest. 1996; 109:540-8.

3. Macarthur AM, Fountain SW. Intracavity suction and drainage in the treatment of emphysematous bullae. Thorax. 1977;32:668-72.

4. Bhattacharyya P, Sarkar D, Nag S, Ghosh S, Roychoudhury S. Transbronchial decompression of emphysematous bullae: a new therapeutic approach. Eur Respir J. 2007;29:1003-6.

5. Snell GI, Holsworth L, Fowler S, Eriksson L, Reed A, Daniels FJ, et al. Occlusion of a broncho-cutaneous fistula with endobronchial one-way valves. Ann Thorac Surg. 2005;80:1930-2.

\title{
Right ventricular outflow tract reconstruction using a valved femoral vein homograft
}

\author{
Pranava Sinha, MD, Sachin Talwar, MCh, Achintya Moulick, MD, and Richard Jonas, MD, Washington, DC
}

Restoration of right ventricle to pulmonary artery continuity in infancy and early childhood may require a conduit. However, appropriately sized pulmonary and aortic homografts in the range of 10 to $16 \mathrm{~mm}$ in diameter are frequently not available. Furthermore, pulmonary and aortic homografts are prone to early calcification, especially of the subvalvar muscle. They also require a hood of supplementary tissue, such as pericardium for the proximal anastomosis. We report our recent experience with the use of an alternative homograft that avoids many of these problems, namely, a valved segment of cryopreserved femoral vein homograft.

\section{CLINICAL SUMMARY}

Tetralogy of Fallot with pulmonary atresia was diagnosed in a 2-month-old girl weighing $5.7 \mathrm{~kg}$, and she was scheduled for elective primary repair. Her central pulmonary ar-

From the Department of Cardiovascular Surgery, Children's National Medical Center, Washington, DC.

Received for publication Sept 2, 2008; accepted for publication Oct 10, 2008; available ahead of print Dec 22, 2008.

Address for reprints: Richard A. Jonas, MD, Chief of Cardiovascular Surgery, Children's National Medical Center, 111 Michigan Avenue, NW, Washington, DC 20010 (E-mail: rjonas@cnmc.org).

J Thorac Cardiovasc Surg 2010;139:226-8

$0022-5223 / \$ 36.00$

Copyright (c) 2010 by The American Association for Thoracic Surgery doi:10.1016/j.jtcvs.2008.10.018 teries were $3 \mathrm{~mm}$ in size. Because of the long-segment pulmonary atresia, interposition of a conduit was necessary; however, an appropriately sized aortic or pulmonary homograft (11-12 mm) was not available. After standard hypothermic cardiopulmonary bypass was established and cardioplegic arrest was achieved, a right ventriculotomy was made and the ventricular septal defect was closed in standard fashion. A 3-mm fenestration was made in the ventricular septal defect patch because of the small size of the pulmonary arteries and incomplete arborization in anticipation of high postoperative right ventricular pressure. An adult cryopreserved femoral vein homograft with diameter tapering from 16 to $11 \mathrm{~mm}$ (Cryolife Inc, Kensaw, GA) was chosen, thawed, and rinsed. The homograft was gently distended with the rinse solution, and a segment 11 to $12 \mathrm{~mm}$ in diameter and $4 \mathrm{~cm}$ in length containing a competent valve (Figure 1) was identified and cut from the $30 \mathrm{~cm}$ of vein available. By taking care to maintain the appropriate direction of flow through the graft, the distal anastomosis to the pulmonary artery was fashioned using continuous 6-0 polypropylene suture. After this, the proximal end of the graft was beveled and anastomosed to the right ventriculotomy using a running 5-0 polypropylene suture. No pericardial hood was necessary.

After the reconstruction, the patient was weaned easily from cardiopulmonary bypass and made an uneventful 